\title{
Health professionals' perspective on the impact of community health care reform in different regions of China
}

\author{
Yanchun Zhang ${ }^{1}$, Jiangmei Qin ${ }^{1}$, Lifang Zhang ${ }^{1}$, Liqun Liu ${ }^{2}$, Wei Zhou ${ }^{2}$
}

\section{Abstract}

Objective: Changes in supplying community health services, degree of satisfaction, and policy suggestions are presented from the perspectives of health professionals in different regions of China with the purpose of further facilitating comprehensive reform of community health services.

Methods: Based on geographic location and economic level of development, eight cities were selected and 12 community health service institutions were chosen by random sampling from each city. A questionnaire survey was conducted by the health professionals.

Results: With respect to working enthusiasm, reduction in antibiotic drug use, social image and trust of patients, more health professionals in middle and western China showed positive feedbacks than those in eastern China. With respect to preliminary results of the reform, performance and salary, and health care insurance policies, health professionals' satisfaction levels in middle and western China were higher than in eastern China. The health professionals in middle and western China were more concerned about equipment, infrastructure and increasing training opportunities. The health professionals in both eastern and middle China accentuated improving the variety of essential drugs covered by health insurance, while health professionals in eastern China suggested performance-related payment reform.

Conclusions: The performance of health professionals in middle and western China was improved more significantly through comprehensive reform than that of health professionals in eastern China. For health professionals in middle and western China, it is essential to strengthen infrastructure and increase professional training, while health professionals in middle and eastern China would like to see an increase in the variety of essential drugs, and those in eastern China require strengthening performance-related payment reform.

Keywords: Community health care, Health care reform, Health professional, Impact analysis, performance-related payment, Essential drugs

\section{Introduction}

In April 2009, the "Opinions of CPC Central Committee and State Council on deepening the reform of the medical and health" (referred to as the "New Medical Reform") proposed that urban and rural grassroots medical and health service systems should be further improved, and that the general target of the basic public health services should be popularized [1]. In 2013, the General Office of the State Council issued the "Opinions on the Consolidation and Improvement in the
1. National Health Development Research Centre, Beijing 100191, China

2. Department of Maternal and Child Health Care and Community Health, National Health and Family Planning Commission, Beijing 100044, China

CORRESPONDING AUTHOR: Jiangmei Qin

National Health Development Research Centre, Beijing 100191, China

E-mail: qinjm@nhei.cn

Funding: Sino-Australia Health and HIV/AIDS fund project [Project No: FA55 HSS409].

Received 14 October 2013; Accepted 26 December 2013 
Essential Drug System and New Operating Mechanism for Grassroots Health Care System." This was the second time a suggestion had been made to strengthen the construction of the grassroots health service system, with the aim of improving the service ability, and consolidating the grassroots medical and health service network [2]. However, the current status of community health services in the urban area varies from eastern China to middle and western China, as does the development of comprehensive reform. As the representative service provider, community medical personnel are important stakeholders in the comprehensive reform of community health services and key performers in improving the capacity of the community health service. Their understanding, satisfaction and suggestions regarding comprehensive reform are directly related to the implementation of community health care policy, the quality of service, and the satisfaction of the residents [3]. Comprehensive reform of community health care in eight typical cities was therefore systematically studied, and changes in community health care before and after the "New Medical Reform" were evaluated. The evaluation of the medical personnel regarding the reforms and their suggestions for further work were recorded. This provides a basis for decisionmaking for promoting the sound development of community health services in different regions of China and for boosting the progress of comprehensive reform.

\section{Methods}

\section{Study subjects}

Eight cities from eastern China (Hangzhou and Wuxi), middle China (Hefei, Tongling, and Wuhan), and western China (Chengdu, Baoji, and Shihezi), were sampled. Twelve community health service centers were selected for each city, using a random sampling method. A questionnaire survey was distributed to all medical personnel on duty in each community health service center.

\section{Method}

Medical students and community health service personnel were selected as investigators to collect data from the community medical personnel, following a pilot survey and the unified training of the research group. The investigation included four parts. (1) Demographic indicators, such as sex, age, and title of the medical personnel. (2) Changes in individual work after implementation of the reform, including the working environment, training opportunities, working enthusiasm, workload, revenue pressure, use of essential drugs, use of antibiotics, types of prevention and health care services, and the initiative service items. (3) Satisfaction of medical personnel after the comprehensive reform of community health care in terms of the working environment, training, income, personnel system (staffing and recruiting), essential drug system, performance appraisal, basic public health service, and medical insurance policy. The satisfaction evaluation was performed using a 5-point method ("very satisfied," "satisfied," "general," "not satisfied," and "very dissatisfied"). An "uncertain/not clear" option was also added. The degree of satisfaction was calculated by designating "very satisfied," "satisfied," and "general" as "satisfactory." (4) Suggestions of the Medical Personnel for the Improvement of Comprehensive Reform of Community Health Care.

\section{Statistical methods}

The survey data were doubly entered by EpiData 3.0 using SPSS 17.0 software for statistical analysis. The count data were analyzed by a $\chi^{2}$ test with multiple comparisons of the sample rate. The inspection level of the comparison between three groups was an $\alpha=0.05$ and the pairwise comparison was $\alpha=0.0125$.

\section{Results}

\section{Subject demographics}

There were 2434 community medical personnel enrolled in this study. A total of 2434 questionnaires were issued and 2434 valid questionnaires were collected, giving an effective recovery rate of $100.0 \%$. There were 991, 798, and 645 subjects investigated from eastern, middle, and western China, respectively, accounting for $40.7 \%, 32.8 \%$, and $26.5 \%$ of the total, respectively. The subjects were an average of 36.1 years of age, and included 1784 women (73.3\%) and 650 men (26.7\%). The subjects' levels of education were as follows: 581 (23.9\%), below junior college; 1025 (42.1\%), junior college; and 828 $(34.0 \%)$, undergraduate and above. The subjects' types of work were as follows: 657 general practitioners (27.0\%); 224 specialists (9.2\%); 718 nurses $(29.5 \%) ; 251$ public health care 
workers $(10.3 \%)$; 482 other technical personnel (19.8\%); and 102 administrators $(4.2 \%)$.

\section{Evaluation by medical personnel of community health care work before and after mdical reform in eastern, middle, and western China}

As shown in Table 1, there were significant differences in the evaluations submitted by the medical personnel regarding the working environment, training opportunities, work enthusiasm, workload, revenue pressure, proportion of essential drugs, reduction in the use of antibiotics, prevention and health care services, initiative service, income, social image, and degree of trust by residents $(P<0.05)$. A higher proportion of medical personnel in middle China than in eastern China held the view that the working environment, training opportunities, proportion of essential drugs, prevention and health care services, initiative service, and income were improved after the reform. The proportion of medical personnel in middle China who subscribed to the view that the prevention and health care services, initiative service, and income were improved after the reform was higher than the proportion in western China, while the proportion in western China who subscribed to the view that work enthusiasm, workload, and revenue pressure were increased by the reform was higher than the proportion in eastern and middle China. The proportion of medical personnel in western China who subscribed to the view that the essential drug proportion was increased, antibiotic use was decreased, income was increased, and social image and trust by residents were improved was higher than in eastern China. These differences were statistically significant $(P<0.0125)$.

\section{Satisfaction of medical personnel in eastern, middle, and western China towards all aspects of compre- hensive reform of community health care}

There were no significant differences in the evaluation of working environment, training opportunities, personnel system, essential drug system, and basic public health service by medical personnel in eastern, middle, and western China $(P>0.05)$. However, there were significant differences in the evaluation of primary effectiveness of comprehensive reform, income, performance appraisal, and medical insurance policy $(P<0.05)$. Pairwise comparisons of the degree of satisfaction of medical personnel towards the primary effectiveness of the comprehensive reform of community health care in eastern, middle, and western China were significantly different $(P<0.0125)$. Satisfaction with income in middle cities reached a maximum of $65.2 \%$, which was higher than those in eastern $(56.3 \%)$ and western cities $(56.9 \%)$. Satisfaction with the implementation

Table 1. Community health worker evaluations of community health care services before and after health reform in eastern, middle, and western China $[n(\%)]$

\begin{tabular}{|c|c|c|c|c|c|}
\hline & $\begin{array}{l}\text { Eastern cities } \\
(n=991)\end{array}$ & $\begin{array}{l}\text { Middle cities } \\
(n=798)\end{array}$ & $\begin{array}{l}\text { Western cities } \\
(n=645)\end{array}$ & $\chi^{2}$ value & $P$ value \\
\hline Better working environment ${ }^{* \Delta}$ & $532(53.7)$ & $603(75.6)^{\Delta}$ & $471(73.0)^{\Delta}$ & 112.585 & 0.000 \\
\hline Increase in training ${ }^{*}$ & $426(43.0)$ & $412(51.6)^{\Delta}$ & $290(45.0)$ & 13.884 & 0.001 \\
\hline Higher working enthusiasm ${ }^{*}$ & 415 (41.9) & $487(61.0)^{\Delta}$ & $409(63.4)^{* \Delta}$ & 95.526 & 0.000 \\
\hline Greater workload $^{* \Delta}$ & $788(79.5)$ & $618(77.4)^{\Delta}$ & $565(87.6)^{* \Delta}$ & 25.327 & 0.000 \\
\hline Higher revenue pressure ${ }^{* \Delta}$ & $439(44.3)$ & $441(55.3)^{\Delta}$ & $410(63.6)^{* \Delta}$ & 59.837 & 0.000 \\
\hline Higher proportion of essential drugs ${ }^{* \Delta}$ & $556(56.1)$ & $544(68.2)^{\Delta}$ & $440(68.2)^{\Delta}$ & 36.288 & 0.000 \\
\hline Less use of antibiotics ${ }^{* \Delta}$ & $484(48.8)$ & $451(56.5)^{\Delta}$ & $370(57.4)^{\Delta}$ & 15.073 & 0.001 \\
\hline More prevention and health care services ${ }^{*}$ & $678(68.4)$ & $652(81.7)^{\Delta}$ & $468(72.6)^{*}$ & 40.927 & 0.000 \\
\hline More initiative service* & $775(78.2)$ & $685(85.8)^{\Delta}$ & $494(76.6)^{*}$ & 23.996 & 0.000 \\
\hline 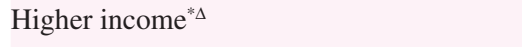 & $206(20.8)$ & $340(42.6)^{\Delta}$ & $208(32.2)^{* \Delta}$ & 98.806 & 0.000 \\
\hline Better social image ${ }^{* \Delta}$ & $491(49.5)$ & $532(66.7)^{\Delta}$ & $454(70.3)^{\Delta}$ & 87.911 & 0.000 \\
\hline Higher trust degree ${ }^{* \Delta}$ & $407(41.1)$ & $504(63.2)^{\Delta}$ & $437(67.6)^{\Delta}$ & 140.448 & 0.000 \\
\hline
\end{tabular}

Note: Compared with eastern cities, ${ }^{\Delta} P<0.0125$; compared with middle cities, ${ }^{*} P<0.0125$. 
of performance appraisal in middle (73.4\%) and western cities (73.0\%) was higher than in eastern cities $(68.2 \%)$. Satisfaction with medical insurance policy in eastern cities was $80.9 \%$, which was lower than in middle $(86.7 \%)$ and western cities $(87.7 \% ; P<0.0125$, Table 2$)$.

\section{Improvements in subsequent reform of community health service institutions as regarded by medical personnel in eastern, middle, and western China}

Medical personnel in eastern cities believed that the top three improvements should include performance-based incomesystem reform (58.6\%), strengthening of the infrastructure (46.7\%), and an increase in essential drugs (41.9\%). Health professionals in middle cities considered that the top three improvements should include strengthening of the infrastructure $(56.4 \%)$, an increase in essential drugs $(51.1 \%)$, and an increase in training opportunities (46.2\%). Health professionals in western cities suggested that the top three improvements should include performance-based income-system reform (51.6\%), an increase in training opportunities $(51.0 \%)$, and strengthening of the infrastructure $(50.4 \%)$. With respect to the suggestions proposed by community medical personnel in eastern, middle, and western China regarding further reform, there were no significant differences in the proposed increases in public health service items $(P>0.05)$. However, there were significant differences in the proposed strengthening of the infrastructure, increase in training opportunities, increase in the types of essential drugs, reform of the personnel distribution system, reform of the performance-based income system, combining general medical fees, and increase in the proportion of reimbursement among the different regions $(P<0.05)$. The demand of medical personnel in eastern China for the implementation of performance-based income reform was stronger than the demands of medical personnel in middle and western China. The suggestions of medical personnel in middle China for an increase in types of essential drugs were more frequent than similar demands by medical personnel in eastern and western China. More medical personnel in middle China mentioned the importance of strengthening of infrastructure and training opportunities than in eastern China. The demand of the medical personnel in the western cities for the increase in training opportunities was stronger than in eastern China $(P<0.0125$; Table 3$)$.

\section{Discussion}

Implementation of the comprehensive community health care reform resulted in greater improvements in the performances of community health professionals in middle and western China than in eastern China Improvements in the performance of community health professionals in middle and western China were greater than in eastern cities, which mainly manifested as a higher work enthusiasm, a decrease in the proportion of antibiotic use, a better social image, and improvement in the degree of trust by

Table 2. Community health worker satisfaction towards the community health care reform in eastern, middle, and western China $[n(\%)]$

\begin{tabular}{|c|c|c|c|c|c|}
\hline & $\begin{array}{l}\text { Eastern cities } \\
(n=991)\end{array}$ & $\begin{array}{l}\text { Middle cities } \\
(n=798)\end{array}$ & $\begin{array}{l}\text { Western cities } \\
(n=645)\end{array}$ & $\chi^{2}$ value & $P$ value \\
\hline Primary effectiveness of comprehensive reform & $762(76.9)$ & $651(81.6)^{\Delta}$ & $534(82.8)^{* \Delta}$ & 9.784 & 0.008 \\
\hline Working environment & $901(90.9)$ & $735(92.1)$ & $596(92.4)$ & 1.058 & 0.589 \\
\hline Training opportunities & $833(84.1)$ & $679(85.1)$ & $529(82.0)$ & 2.801 & 0.247 \\
\hline Income & $558(56.3)$ & $520(65.2)^{\Delta}$ & $367(56.9)^{* \Delta}$ & 16.564 & 0.000 \\
\hline Personnel system & $704(71.0)$ & $576(72.2)$ & $435(67.4)$ & 4.363 & 0.113 \\
\hline Implementation of the essential drug system & $814(82.1)$ & $657(82.3)$ & $552(85.6)$ & 3.419 & 0.181 \\
\hline Performance appraisal & $676(68.2)$ & $586(73.4)^{\Delta}$ & $471(73.0)^{\Delta}$ & 6.971 & 0.031 \\
\hline Basic public health service & $841(84.9)$ & $687(86.1)$ & $547(84.8)$ & 0.689 & 0.709 \\
\hline Medical insurance policy & $802(80.9)$ & $692(86.7)^{\Delta}$ & $566(87.8)^{* \Delta}$ & 17.077 & 0.000 \\
\hline
\end{tabular}

Note: Compared with the eastern cities, ${ }^{\Delta} P<0.0125$; compared with the middle cities, ${ }^{*} P<0.0125$. 
Table 3. Community health worker suggestions on community health care reform in eastern, middle, and western China $[n(\%)]$

\begin{tabular}{|c|c|c|c|c|c|}
\hline & $\begin{array}{l}\text { Eastern cities } \\
(n=991)\end{array}$ & $\begin{array}{l}\text { Middle cities } \\
(n=798)\end{array}$ & $\begin{array}{l}\text { Western cities } \\
(n=645)\end{array}$ & $\chi^{2}$ value & $P$ value \\
\hline Strengthening of the infrastructure & $463(46.7)$ & $450(56.4)^{\Delta}$ & $325(50.4)$ & 16.480 & 0.000 \\
\hline Increasing training opportunities & $359(36.2)$ & $369(46.2)^{\Delta}$ & $329(51.0)^{\Delta}$ & 38.053 & 0.000 \\
\hline Increasing types of essential drugs & 415 (41.9) & $408(51.1)^{\Delta}$ & $234(36.3)^{*}$ & 33.825 & 0.000 \\
\hline Reform of personnel distribution system & $361(36.4)$ & $278(34.8)$ & $270(41.9)^{* \Delta}$ & 7.942 & 0.019 \\
\hline Reform of performance-based income system & $581(58.6)$ & $356(44.6)^{\Delta}$ & $333(51.6)^{* \Delta}$ & 35.221 & 0.000 \\
\hline Combining medical fees & $125(12.6)$ & $104(13.0)^{\Delta}$ & $120(18.6)^{* \Delta}$ & 12.915 & 0.002 \\
\hline Improvement in reimbursement proportion & $197(19.9)$ & $228(28.6)^{\Delta}$ & $165(25.6)^{\Delta}$ & 18.908 & 0.000 \\
\hline Increasing public health service items & $109(11.0)$ & $72(9.0)$ & $69(10.7)$ & 2.054 & 0.358 \\
\hline
\end{tabular}

Note: Compared with eastern cities, ${ }^{\Delta} P<0.0125$; compared with middle cities, ${ }^{*} P<0.0125$.

residents. The medical personnel were quite satisfied with the primary effectiveness of comprehensive reform and the medical insurance policy.

Before the reform, the eastern cities with a good economic foundation had taken the lead in establishing a community health management system and had explored the operational mechanisms, such as the comprehensive reform of the grassroots medical and health care institutions by adopting "separation of revenues and expenditures" as the core in Hangzhou in 2006. This resulted in the strengthening of the government's financial security; however, these systems were mainly carried out by non-governmental institutions, with little government support [4]. After 2009, the community health service institutions in middle and western China were greatly supported by the government in terms of human and financial resources and related policies, as a result of the implementation of "New Medical Reform." Operating mechanism reform was also explored. First, public health service funding has increased year-by-year. "Opinions on the Promotion of the Equalization of Basic Public Health Service" pointed out that the funding for basic public health services was at least 15 Yuan per capita in 2009, at least 20 Yuan per capita in 2011, and 30 Yuan per capita in 2013 [5]. Second, standardization construction of the community health service institutions in each region was continuously promoted. In 2011, standardization construction of the community health service institutions in Hefei was incorporated into the livelihood project. Baoji city in Shaanxi Province invested 45 million Yuan in improving the equipment configuration of the community health services institution for 3 consecutive years (2008-2010). In addition, some regions also made beneficial explorations into reforming the operating mechanisms of non-governmental community health service institutions. For example, Tongling city adopted a strategy whereby the staff of non-governmental and governmental institutions could enjoy the same policies and investments [6]. The low starting point for the reform and rich reform content in middle and western China means that medical personnel are more satisfied with the reform effectiveness than personnel in eastern China.

Infrastructure and training opportunities are expected to be strengthened and increased in middle and western China, while the types of essential drugs are suggested to be increased in eastern and middle China

Performance-based income reform was most strongly demanded in eastern China, while strengthening of the infrastructure was most strongly demanded in middle China. This difference is related to the high economic development and relatively good infrastructure in eastern China; however, the infrastructure in western cities depends largely on funding from central government. There is much less investment in the infrastructure in middle China. Medical personnel in middle and western China expect to increase their training opportunities, which is directly related to the weak talent base. 
An increase in the types of essential drugs was strongly demanded by medical personnel in middle and eastern China. The limited number of categories of essential drugs remains one of the main problems after the implementation of the essential drug system. The drug varieties in the catalogue of essential community drugs should be at least 700 [7]. However, in 2009, there were only 307 varieties in the catalogue of national essential drugs. Although the majority of provinces throughout the country have supplemented the catalogue [8], the varieties still fail to meet the demands of the residents.

\section{Medical personnel in eastern China strongly demand the reform of performance-based income system}

Based on the evaluation, only $20.8 \%$ of the medical personnel in eastern China claimed that their incomes had increased, and $41.9 \%$ believed that their work enthusiasm had been promoted, accounting for the lowest proportion of all regions. The satisfaction of medical personnel in eastern cities with their income was the lowest, and "performance-based income reform" was the most strongly demanded suggestion by medical personnel in eastern China, corresponding with the income distribution index.

With respect to performance-based income reform, the related study also indicates that the current performance-based income reform of medical institutions is not perfect. First, there is a lack of an effective appraisal mechanism for performance-based income and a lack of any departmental performance management system to consider performance planning, evaluation, analysis, and improvement. Second, it is difficult to quantify the comprehensive management index and to ensure fairness. Third [9], after implementation of the essential drug system, it is difficult to implement performance-based incomesystem reform because of the decrease in the drug-related income of the community health service institutions, insufficient staffing, and incomplete government compensation [10].

\section{Policy suggestions}

The infrastructure should be strengthened, and training should be supported in middle and western China through financial transfer and regional cooperation

Compared with eastern cities, the economy in middle and western China is still relatively backward with a weak community health service base. Investments in the infrastructure and training in China mainly focus on the sessional project in middle and western China, and there is a lack of sustainability. First, it has been suggested that the financial transfer of payments into projects supporting infrastructure construction, equipment purchase, and training in middle and western China should be increased and sustained. Second, exchange and cooperation between middle, western, and eastern cities should be promoted, thus encouraging support from eastern cities for western cities in terms of training. Third, medium- and long-term planning of infrastructure construction and training in middle and western China should be developed to promote the comprehensive, balanced, and sustainable development of the nationwide community health service.

\section{The essential drug system should be improved to meet the requirements of community drug use}

The drug use requirement of medical personnel is a true reflection of the residents' needs. The fact that drug use requirements cannot meet the actual needs even after the implementation of the essential drug system remains a problem. It has therefore been suggested that the essential drug system should be further improved and the types of essential drugs should be increased to meet the drug-use requirements of the medical personnel. It is stipulated that community health service institutions must use the community essential drug catalogue, but should determine the proportion of drugs outside the catalogue depending on the need [11]. Financial compensation by the government for essential drugs should be implemented, thus avoiding the problem of insufficient drug supply due to incomplete drug compensation.

\section{Reform of operating mechanisms should be further promoted, with the strengthening of reforms of performance appraisal and performance-based income system}

First, regarding the performance-based income system reform, the overall income level of medical personnel should be at least equal to that before the reform. Second, international experience should be heeded. An internal assessment should be performed using indices such as the number of services, 
service quality, degree of satisfaction of the residents and medical expenditures $[12,13]$ to achieve a more reasonable income-distribution system. Third, the "guaranteed but not capped" policy should be implemented for the performance appraisal of institutions, thus encouraging the institutions to increase their total performance-based income and to improve the work enthusiasm of the medical personnel.

\section{Conflict of interest}

The authors declare no conflict of interests.

\section{References}

1. "Opinions of the CPC Central Committee and the State Council on Deepening the Medical and Health Care System Reform." 2009;3-17.

2. General Office of the State Council. "Opinions about the Consolidation and Improvement in the Essential Drug System and New Grassroot Operating Mechanism" [EB/OL]. http:// www.moh.gov.cn/mohzcfgs/s9660/201302/ec44be6a90c945459820f54a4ad9e6ef.shtml.

3. Yin $\mathrm{W}$, Wang $\mathrm{K}, \mathrm{Fu} \mathrm{H}$. Job satisfaction and stability study of community health professionals. Chin J Hosp Admin 2003; 19:351-5

4. Zhao K, Zhang Y, Yao H. A comparative study on the service delivery of community health service institutions of different ownerships. Chin Gen Pract 2010;13ue 8A:2430-2.

5. National Health and Family Planning Commission of the People's Republic of China. Notice on the Work of National Basic
Public Health Service Project in 2013. http://www.nhfpc.gov.cn/ jws/s3577/201306/b035feee67f9444188e5123baef7d7bf.shtml.

6. Department of Maternal and Child Health of the Ministry of Health. China National Health Development Research Centre of the Ministry of Health. Experience Exchange Materials of the Seminar on the Comprehensive Reform of Community Health Care. March 2012.

7. WHO. Access to affordable essential medicines. http://www. who.int/medicines/mdg/MDG08ChapterEMedsEn.pdf.

8. Website of the Ministry of Health in the People's Republic of China. Meeting on the Standardization of Provincial Drug Supplement Work Held by the Drug Administration of the Ministry of Health. http://www.moh.gov.cn/publicfiles/business/htmlfiles/ mohywzc/s3582/201106/52013.htm, 2011-06-13.

9. Chen J, Sun A, Liu X. Discussion on the problems and management countermeasures existing in the performance wage distribution of public hospital. China Medical Herald 2012;9:161-2.

10. Huang Y. Situation analysis of the performance-based income reform in grassroot hospitals. Chin J Rural Health Manag 2012;23:341-2.

11. Zhang Y, Dang Y, Zhao K, Liu Q. An analysis in the Stakeholder of the Drug Policy Implementation of Community Health Service. Chinese Journal of Health Policy Research 2010;3:47-51.

12. Martin-Misener R, McNab J, Sketris IS, Edwards L. Collaborative practice in health systems change: The Nova Scotia experience with the strengthening primary care initiative. Can J Nurs Leadersh 2004;17:33-45.

13. NICE clinical guideline 34. Hypertension: management of hypertension in adults in primary care. National Institute for Health and Clinical Excellence, 2004. 